\title{
Prophylactic effects of ephedrine, ondansetron and ringer on hemodynamic changes during cesarean section under spinal anesthesia - a randomized clinical trial
}

\author{
Mohsen Sabermoghaddam Ranjbar, Shima Sheybani, Fatemeh Jahanbin \\ Mashad University of Medical Sciences, Iran
}

\begin{abstract}
Objectives: Hemodynamic change during spinal anaesthesia for cesarean section is prevalent. Comparing the prophylactic effects of ephedrine, ondansetron and ringer on hemodynamic changes in patients undergoing cesarean section with spinal anaesthesia.

Material and methods: This randomized clinical trial was carried out on pregnant women undergoing elective cesarean section referred to teaching hospitals of Mashhad, Iran. Patients allocated to three groups of intravenous ondansetron (O) $(4 \mathrm{mg}$, $5 \mathrm{~min}$ ),intramuscular ephedrine (E) (25 mg, $25 \mathrm{~min})$ and ringer (R) $(500 \mathrm{~mL}, 20 \mathrm{~min})$ prior to spinal anaesthesia. Anaesthesia inducted with 10-15 mg of bupivacaine. Vital signs were recorded every 3 minutes for 18 minutes including systolic blood pressure (SBP), diastolic blood pressure (DBP), mean arterial pressure (MAP), pulse rate (PR), pulse oximetry $\left(\mathrm{SpO}_{2}\right)$.

Results: Ninety patients with a mean age of $29.4 \pm 5.4$ years were studied in three groups of $O(n=30), E(n=30), R(n=30)$. Results showed a statistically significant difference in the incidence rate of hypotension 12 minutes after spinal anaesthesia in the three groups, but no statistically significant difference was found in the rest of minutes among the three groups. During follow-up minutes, bradycardia was observed in only one patient (1.1\%) of Group $\mathrm{O}$ and no cases of this sign were observed in other minutes and other groups.

Conclusions: Intramuscular administration of ephedrine 25 minutes prior to the spinal anaesthesia leads to better prevention of systolic blood pressure changes compared with intravenous ondansetron and ringer, while administration of ondansetron and ringer had the same effects on reducing hemodynamic changes.
\end{abstract}

Key words: hemodynamic changes, ondansetron, ringer, ephedrine, cesarean section, spinal anesthesia

Ginekologia Polska 2018; 89, 8: 453-458

\section{INTRODUCTION}

Cesarean section is the most common gynecologic surgery, which is called epidemic of cesarean section by many researchers [1]. The most widely used anaesthetic techniques in this surgery are spinal anaesthesia [2]. Spinal anaesthesia has a rapid onset and makes a dense nerve block, which is the best method of anaesthesia in terms of fetal and maternal complications [3, 4]. However, hypotension and bradycardia are two important issues that no definitive preventive method has been defined for them, yet.
Hypotension subsequently could lead to clinical symptoms such as nausea and vomiting, shortness of breath and decreased blood flow through the placenta and deterioration of infant status if not treated appropriately [5]. According to previous studies, the incidence rate of hypotension after spinal anaesthesia (SA) for cesarean is between $12.5 \%$ and $85 \%$, and the incidence rate of bradycardia has been reported $2.5 \%$ in a study [6-8].

Although some therapeutic interventions such as phenylephrine, angiotensin, glycopyrrolate, dopamine and 
crystalloid, as well as, physical methods such as leg compression and elevation have been proposed, none of these methods has resulted in the elimination of maternal hypotension during spinal anaesthesia for cesarean section [3]. Ephedrine is commonly used for both prevention and treatment of hypotension during spinal anesthesia, but there are few studies regarding the prophylactic effect on hypotension and bradycardia compared with other pharmaceutical compounds [9]. Ondansetron is a drug recently showed to impede Bezold-Jarisch reflex (BJR) through modulation of 5 -HT3 receptors [3]. To the best of our knowledge, just one study has so far compared ephedrine and ondansetron taking into account the prophylactic effect of hypotension thus there is an open era for more investigations [10].

This study was conducted to compare the prophylactic effects of ephedrine, ondansetron and ringer to control hemodynamic changes in patients undergoing cesarean section with spinal anaesthesia.

\section{MATERIAL AND METHODS}

\section{Study design and setting}

This randomized triple-blind clinical trial was carried out on pregnant women undergoing elective cesarean section referred to Obstetrics and Gynaecology epartment at two large tertiary centres of Ghaem and Imam Reza in Mashhad, Iran.

\section{Participants}

Women with singleton or twin pregnancies aged 18 to 40 years in ASA class I and II who were candidates for elective or emergency cesarean section with spinal anaesthesia were enrolled in the study. Other inclusion criteria were no history of treatment with anti-migraine drugs or MAO inhibitors or SSRI, no known hypersensitivity to ondansetron, the absence of psychological disorders and lack of addiction to drugs or alcohol. Exclusion criteria were unsuccessful spinal anesthesia, pain untreatable with 50 micrograms of fentanyl after starting surgery, bleeding more than expected ( $500 \mathrm{cc}$ in singleton and $1000 \mathrm{cc}$ in twin), anesthetic level rise over dermatome T4 based on skin test, the need to extend surgical incision due to intraoperative complications and the occurrence of any major surgical or anesthetic complication.

\section{Sampling}

The sample size was estimated at 90 patients (3 groups of 30 subjects) using the formula of comparing two proportions and considering $\alpha=5 \%, \beta=20 \%, Z(1-\alpha / 2)=1.96$, SD1 $=4.00$, SD2 $=4.00$. The samples were selected by simple random sampling method.

\section{Interventions}

The patients were assigned by randomized block design to one of three groups of $\mathrm{O}$ (ondansetron), $\mathrm{E}$ (ephedrine), and $\mathrm{R}$ (ringer). Group $\mathrm{O}$ received $4 \mathrm{mg}$ ondansetron (Tehran Chemie Pharmaceutical Co., Iran) 5 minutes before SA, Group E received $25 \mathrm{mg}$ IM ephedrine (STEROP-BELGIUM Co.) 25 minutes before $\mathrm{SA}$ and Group $\mathrm{R}$ received $500 \mathrm{ml}$ ringer (Samen Pharmaceutical Co., Mashhad, Iran) $20 \mathrm{mi}-$ nutes before SA.

\section{Data collection}

Information such as age, weight, height, body mass index, history of previous delivery and the type of anaesthesia were recorded using a checklist before entering the operating room. Then according to standard conditions, systolic and diastolic blood pressure, MAP, $\mathrm{PR}$ and $\mathrm{SpO}_{2}$ were measured using multi-function compact monitor device (Sazgan Gostar Co., Iran). Venipuncture was performed for all patients with $18 \mathrm{G} \mathrm{IV} \mathrm{catheter.} \mathrm{The} \mathrm{patients} \mathrm{received} \mathrm{the}$ required intervention on admission to the operating room by a nurse who was unaware of the study design. The temperature of the room kept the same among all patients during the study.

\section{Spinal anaesthesia}

Spinal anaesthesia inducted in sitting position with 10-15 mg of hyperbaric bupivacaine $0.5 \%$ (Marcaine_, AstraZeneca, So" derta" lje Sweden) through L3-L4, L4-L5 or L5-S1 spaces using 25-gauge Quincke spinal needle. Thus, $10 \mathrm{mg}$ of bupivacaine was used in patients with a height $<175 \mathrm{~cm}$. and $15 \mathrm{mg}$ bupivacaine in patients with a height of more than $175 \mathrm{~cm}$. The patients were placed in supine position with 15 -degree left tilt and $15 \mathrm{~mL} / \mathrm{kg} / \mathrm{h}$ of ringer was infused until the end of the surgery. This method was performed similarly for all patients in the three groups.

\section{Follow-up}

After SA, every 3 minutes for 18 minutes $\left(3^{\text {rd }}, 6^{\text {th }}, 9^{\text {th }}\right.$, $12^{\text {th }}, 15^{\text {th }}$ and $18^{\text {th }}$ ) vital signs were recorded, including systolic blood pressure (SBP), diastolic blood pressure (DBP), mean arterial pressure (MAP), pulse rate (PR) and pulse oximetry $\left(\mathrm{SpO}_{2}\right)$. The sensory level was assessed bilaterally with a $25 \mathrm{G}$ needle as pinprick test in midclavicular line every two minutes till the level of sensory block stabilized in two consecutive examinations, representing the highest anaesthetic level. Reduction in MAP more than $20 \%$ of baseline records and fall of systolic blood pressure to less than $90 \mathrm{~mm} \mathrm{Hg}$ at any stage of the process was treated with $6 \mathrm{mg}$ of intravenous ephedrine and recorded as hypotension. If PR decreased to less than 50 per minute considered as bradycardia then 0.5 atropin administered to treat this complication.After starting the surgery, the surgical site pain was treated with 50 micrograms of fentanyl,if any. Continuing the pain, spinal anaesthesia considered as unsuccessful, general anaesthesia induced and the case excluded from the study. 


\section{Outcomes}

In this study, the primary outcome measure was to compare the incidence rate of hypotension and bradycardia among the three groups. The second outcome was the pattern of changes in each hemodynamic variable among the three groups. The third outcome was the incidence rate of nausea-vomiting and shivering among the three groups.

\section{Statistical analysis}

Quantitative variables were expressed as mean \pm SD and categorical variables as number and percentage. Data normality was analyzed using One Sample Kolmogorov-Smirnov Test with Modified Lilliefors Test and then the appropriate statistical test was selected. The repeated measure ANOVA was recruited to compare the changes trend in hemodynamic parameters, ANOVA test to measure the level of hypotension and bradycardia, and chi-square test to compare qualitative variables among the three groups through the SPSS version 18 software (Released 2009. PASW Statistics for Windows, Chicago: SPSS Inc).

\section{Ethical considerations}

Informed consent was obtained from the patients after full explanation. The encoded data of patients, which kept completely confidential, were inserted into statistical software. Ethics Committee of Mashhad University of Medical Sciences approved the research project (code: 931454). In the event of any complication related to the research work, the patients were closely observed and appropriately treated by the researchers. In addition, the study was registered at Iranian Registry of Clinical Trials (www.IRCT.IR) with code of IRCT2015102813159N7 before starting the project.

\section{RESULTS \\ Baseline characteristics}

The study was conducted on 90 patients with a mean age of $29.4 \pm 5.4$ years. There was no statistically significant difference among three groups in terms of age, height, previous medical records including the frequency of cesarean, vaginal delivery and anesthesia (Tab. 1). The three groups were matched for SBP, DBP, MAP, PR, and $\mathrm{SpO}_{2}$ before $\mathrm{SA}$ (Tab. 1).

\section{Nausea-vomiting and shivering}

The incidence rate of nausea was respectively $33.3 \%$, $16.7 \%$ and $10 \%$ in groups of $E$, $R$ and $O(P=0.067)$. In addition, Group R showed the highest incidence rate of shivering (30\%) during the surgery, but no statistical differences were observed among the three groups $(E=13.3 \%, O=10.0 \%, P=0.095)$.

\section{Hypotension and bradycardia}

Overall, the incidence rate of hypotension was reported $15.5 \%(n=14)$ in the third minute, $4.4 \%(n=4)$ in sixth minute, $1.1 \%(n=1)$ in ninth minute, $3.3 \%(n=3)$ in twelfth minute, $2.2 \%(n=2)$ in fifteenth minute and $0 \%$ in eighteenth minute after SA. The results of our study showed statistically significant difference for an incidence rate of hypotension

Table 1. Comparison of baseline characteristics of patients undergoing spinal anaesthesia with different types of interventions

\begin{tabular}{|c|c|c|c|c|}
\hline Variable, unit & $\begin{array}{l}\text { Ephedrine } \\
\qquad(n=30)\end{array}$ & $\begin{array}{l}\text { Ondansetron } \\
\qquad(n=30)\end{array}$ & $\begin{array}{l}\text { Ringer } \\
(n=30)\end{array}$ & p-value \\
\hline Age, year* & $29.2 \pm 5.4$ & $29.7 \pm 5.7$ & $29.3 \pm 5.4$ & 0.928 \\
\hline Height, cm* & $159.7 \pm 5.9$ & $161.0 \pm 4.4$ & $161.2 \pm 5.1$ & 0.478 \\
\hline Operation duration, $\min ^{*}$ & $44.8 \pm 8.2$ & $50.0 \pm 8.2$ & $47.1 \pm 9.8$ & 0.081 \\
\hline \multicolumn{5}{|l|}{ Medical history, n (\%) } \\
\hline History of vaginal delivery & $25(83.3)$ & $27(90.0)$ & $25(83.3)$ & 0.661 \\
\hline History of caesarian section & $26(86.7)$ & $24(80.0)$ & $21(70.0)$ & 0.282 \\
\hline History of previous anesthesia & $27(90.0)$ & $25(83.3)$ & $23(76.7)$ & 0.383 \\
\hline General anesthesia & $7(23.3)$ & $12(40.0)$ & $10(33.3)$ & \multirow{2}{*}{0.224} \\
\hline Regional anesthesia & $20(66.6)$ & $13(43.3)$ & $13(43.3)$ & \\
\hline \multicolumn{5}{|l|}{ Vital signs, mean \pm SD } \\
\hline $\mathrm{SBP}, \mathrm{mmHg}$ & $127.7 \pm 10.2$ & $129.8 \pm 8.5$ & $125.4 \pm 11.2$ & 0.236 \\
\hline $\mathrm{DBP}, \mathrm{mmHg}$ & $82.9 \pm 8.3$ & $79.7 \pm 7.6$ & $79.9 \pm 9.9$ & 0.275 \\
\hline MAP, $\mathrm{mmHg}$ & $96.5 \pm 8.3$ & $96.7 \pm 7.5$ & $122.93 \pm 8.1$ & 0.430 \\
\hline Pulse rate, $\mathrm{n} / \mathrm{min}$ & $96.3 \pm 13.4$ & $93.7 \pm 14.5$ & $91.1 \pm 12.6$ & 0.336 \\
\hline SPO2, \% & $98.7 \pm 0.7$ & $98.0 \pm 3.4$ & $98.7 \pm 0.9$ & 0.340 \\
\hline
\end{tabular}

*These variables are presented as mean \pm SD

$\mathrm{SBP}$ - systolic blood pressure; DBP — diastolic blood pressure; MAP — mean arterial pressure; SPO2 - saturation of pulse oxygenation 
Table 2. Incidence of hypotension in three groups of patients undergoing spinal anaesthesia

\begin{tabular}{|l|c|c|c|c|}
\hline Time points & $\begin{array}{c}\text { Ephedrine } \\
(\mathbf{n = 3 0 )}\end{array}$ & $\begin{array}{c}\text { Ondansetron } \\
(\mathbf{n}=\mathbf{3 0})\end{array}$ & $\begin{array}{c}\text { Ringer } \\
(\mathbf{n}=\mathbf{3 0})\end{array}$ & $\mathbf{p}$-value \\
\hline $\begin{array}{l}\text { Immediately } \\
\text { after SA }\end{array}$ & 0 & 0 & 0 & - \\
\hline 3 mins after SA & $7(23.3)$ & $5(16.6)$ & $2(6.6)$ & 0.205 \\
\hline 6 mins after SA & 0 & $3(10.0)$ & $1(3.3)$ & 0.214 \\
\hline 9 mins after SA & $1(23.3)$ & 0 & 0 & 0.364 \\
\hline $\begin{array}{l}12 \text { mins after } \\
\text { SA }\end{array}$ & 0 & $3(10.0)$ & 0 & 0.045 \\
\hline $\begin{array}{l}15 \text { mins after } \\
\text { SA }\end{array}$ & 0 & $1(3.3)$ & $1(3.3)$ & 0.601 \\
\hline $\begin{array}{l}18 \text { mins after } \\
\text { SA }\end{array}$ & 0 & 0 & 0 & - \\
\hline
\end{tabular}

*These variables are presented as mean \pm SD

SBP - systolic blood pressure; DBP — diastolic blood pressure;

$\mathrm{MAP}$ - mean arterial pressure; SPO2 - saturation of pulse oxygenation;

SA — Spinal anaesthesia

just at the 12th minute after SA in the three groups, but the examination for the rest of the minutes showed no statistically significant difference (Tab. 2). On the other hand, in the whole period of follow-up, bradycardia was observed only in one patient (1.1\%) of Group $\mathrm{O}$ at the 12 th minute after SA $(P=0.214)$ and no cases of the complication was observed in other minutes and in other groups.

\section{Changes in vital signs}

Evaluating the trends indicated that SBP dropped after 3 minutes in all patients of the three groups but the differences were not statistically significant. in group $\mathrm{E}$ systolic blood pressure showed a statistically significant $(P=0.017)$ upward trend after the primary decrease. (Fig. 1). However, the changes in DBP $(P=0.456)$, MAP $(P=0.282)$, PR $(P=0.102)$ and $\mathrm{SpO}_{2}(P=0.716)$ showed no statistically significant differences among the three groups during follow-up minutes (see Fig. 2-5).

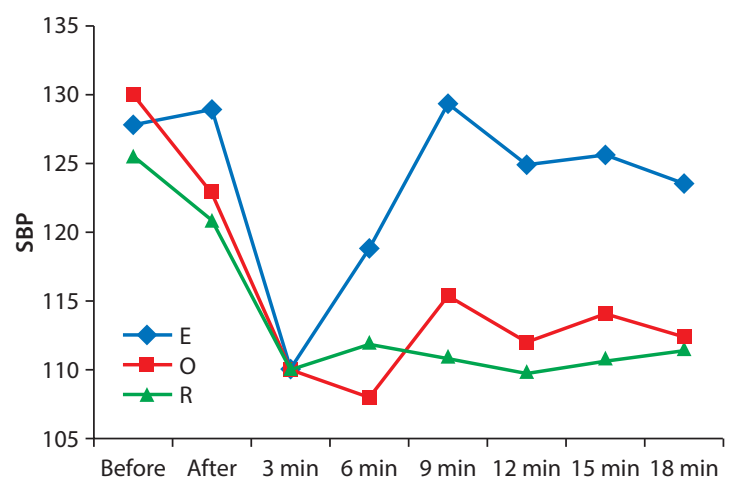

Figure 1. The trend of systolic blood pressure changes $(\mathrm{mmHg})$ in three groups of ephedrine $(E)$, ondansetron $(O)$ and Ringer $(R)$

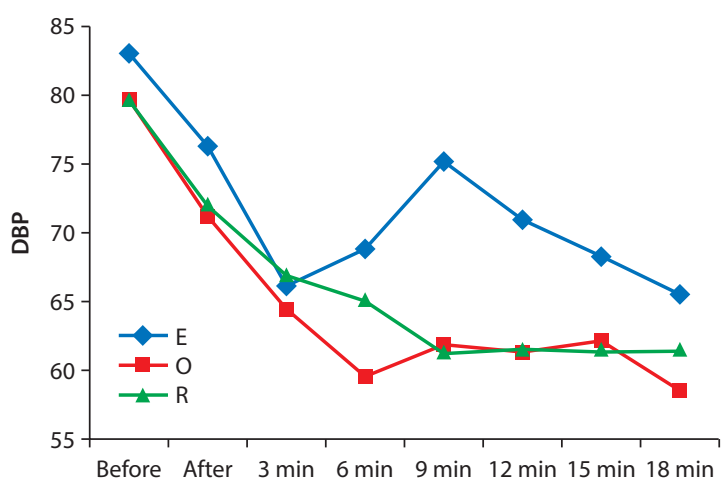

Figure 2. The trend of diastolic blood pressure changes $(\mathrm{mmHg})$ in three groups of ephedrine $(E)$, ondansetron $(O)$ and Ringer (R)

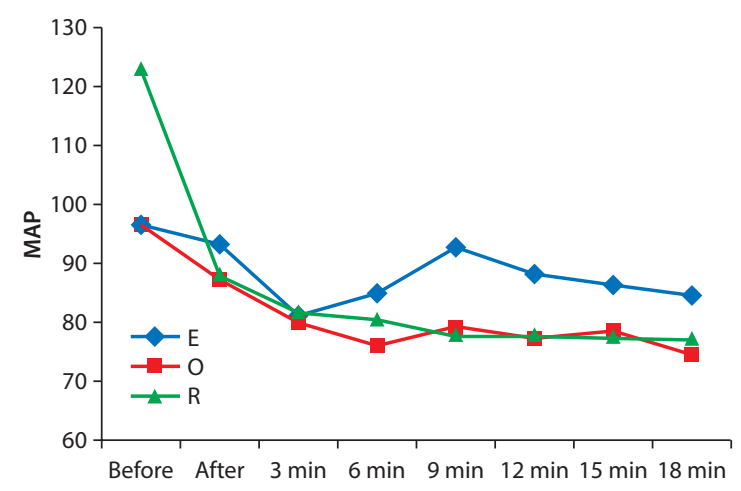

Figure 3. The trend of mean arterial pressure (MAP) changes $(\mathrm{mmHg})$ in three groups of ephedrine $(E)$, ondansetron $(O)$ and Ringer $(R)$

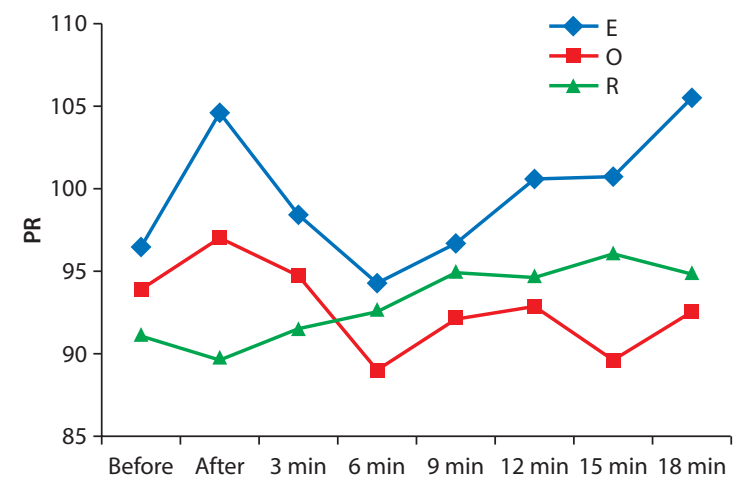

Figure 4. The trend of pulse rate (PR) changes (per minute) in three groups of ephedrine $(E)$, ondansetron $(O)$ and Ringer $(R)$

\section{DISCUSSION}

This study was conducted to compare the efficacy of three pharmaceutical compounds of ephedrine (E), ondansetron $(\mathrm{O})$ and ringer $(\mathrm{R})$ in the prevention of hypotension and bradycardia during spinal anaesthesia for cesarean delivery. The results showed that patients receiving ephedrine before SA bear less time exposed to low systolic blood pressure and systolic hypotension has been quickly compensated, though the incidence rate of hypotension and bradycardia had no significant difference among the three 
intervention groups, except for the 12th minutes after SA that was higher in the ondansetron group.

This is an issue that has been mentioned in a Cochrane systematic review [3], where states that although some therapeutic interventions (such as colloids, ephedrine)reduce the incidence of hypotension, but applying these methods could not led to elimination of the need for treatment of maternal hypotension during spinal anesthesia for cesarean section.

Ephedrine is commonly used to treat hypotension, but there are few studies regarding the prophylactic effect of hypotension and our study is important in this regard. However, the beneficial prophylactic effects of ephedrine have been shown in a few studies, although some studies have pointed to dose-dependent side effects like increased blood pressure and heart rate [3].

In our study, the dosage of ephedrine was $25 \mathrm{mg} \mathrm{IM} 25 \mathrm{mi}-$ nutes before spinal anaesthesia and no case of hypertension (SBP > $160 \mathrm{~mm} \mathrm{Hg}$ or DBP > $95 \mathrm{~mm} \mathrm{Hg}$ ) occurred during follow-up. In addition, no complaints of palpitation were reported by patients though this was not considered as a key variable. However, in the present study, we evaluated other symptoms such as shivering, nausea and vomiting as well, which there were no statistically significant differences among the three groups by the end of follow-up. The finding is in line with a systematic review conducted on the effect of taking ephedrine for SA in patients undergoing cesarean section [9].

In this study, we also examined the effectiveness of intravenous ondansetron as an antagonist of the 5-HT3 receptor. This pharmaceutical category has been widely used by anesthesiologists for the prevention and treatment of postoperative nausea and vomiting (PONV) [11, 12]. According to studies conducted by Owczuk and Sahoo, the 5-HT3 receptor antagonists have been considered as drug candidates that have been able to prevent spinal anaesthesia-induced hypotension. The dose of $4 \mathrm{mg}$ intravenous ondansetron 5 minutes prior to SA was used in our study and its effectiveness compared with ringer showed no significant difference though lower efficiency than ephedrine [13, 14]. Lack of effectiveness of ondansetron in other studies similar to our study has also been mentioned even at a dose of $8 \mathrm{mg}$. In a study by Ortiz-Gómez et al. [15], there was no significant difference in the number of patients with hypotension in placebo group (43.8\%) and groups receiving different doses of $2 \mathrm{mg}$ (53.1\%), $4 \mathrm{mg}$ (56.3\%) and $8 \mathrm{mg}$ (53.1\%) of ondansetron before induction of spinal anesthesia for cesarean delivery $(P=0.77)$. Similar to our results, Marciniak et al. [5] showed that ondansetron is not effective in preventing hypotension and bradycardia. It seems that the reasons for the differences in the results are various criteria to define hypotension and bradycardia, the difference in the dose of ondansetron, time and the route of administration, and combination compared in the control group [3]. Cyna et al. showed 16 criteria for hypotension during meta-analysis in 2006. KIÖHR et al. analyzed the studies between 1999 and 2009 on hypotension during cesarean section and found 15 different definitions of hypotension $[3,16]$.

The nivatpumin study showed no significant difference in maternal blood pressure, which prophylactic ephedrine (10 mg IV) or ondansetron (8 $\mathrm{mg}$ ) were used in spinal anaesthesia for cesarean delivery compared with placebo [10]. This finding is consistent with our results so that we did not find any difference among patients in three groups in terms of the incidence rate of hypotension and bradycardia, except at one point in time. The trend of changes in hemodynamic variables was examined among the three groups in our study, which is superior in this respect compared to other studies. However, further studies are needed to understand the effectiveness of ondansetron and ephedrine as well as effects of these drugs and other vasoconstrictors in preventing hypotension.

\section{Study limitations}

In this study, we did not examine the relation of sensory block with the primary outcome measure

\section{CONCLUSIONS}

According to the results obtained, all three intervention modalities are the same in terms of prevention of hypotension and bradycardia after spinal anaesthesia for cesarean delivery, so that no case of significant hypotension needing rescue intervention seen. However, a dose of $25 \mathrm{mg}$ of intramuscular ephedrine 25 minutes prior to SA can lead to a better control of the trend of changes in systolic blood pressure compared with $4 \mathrm{mg}$ of intravenous ondansetron or traditionally used $500 \mathrm{ml}$ of the ringer.

\section{Acknowledgement}

This study has been adapted from the research project (code: 931454) and PhD thesis by Fatemeh Jahanbin in the field of anesthesiology. Research Deputy of Mashhad University of Medical Sciences, Iran, funded the present study

\section{REFERENCES}

1. Flamm BL. Cesarean section: a worldwide epidemic? Birth. 2000; 27(2): 139-140, indexed in Pubmed: 11251493.

2. Riley ET, Cohen SE, Macario A, et al. Spinal versus epidural anesthesia for cesarean section: a comparison of time efficiency, costs, charges, and complications. Anesth Analg. 1995; 80(4): 709-712, indexed in Pubmed: 7893022.

3. Emmett RS, Cyna AM, Andrew M, et al. Techniques for preventing hypotension during spinal anaesthesia for caesarean section. Cochrane Database Syst Rev. 2001(3): CD002251, doi: 10.1002/14651858.CD002251, indexed in Pubmed: 11687021.

4. Hajian P, Malekianzadeh B, Davoudi M. Efficacy of Intravenous Ondansetron on Hemodynamic Complications in Women Undergoing Spinal Anesthesia for Cesarean Section: A Randomized Placebo Controlled Clinical Trial. Galen Medical Journal. 2016; 5(1): 13-18.

5. Marciniak A, Owczuk R, Wujtewicz $M$, et al. The influence of intravenous ondansetron on maternal blood haemodynamics after spinal 
anaesthesia for caesarean section: a double-blind, placebo-controlled study. Ginekol Pol. 2015; 86(6): 461-467, indexed in Pubmed: 26255456.

6. French GW, White JB, Howell SJ, et al. Comparison of pentastarch and Hartmann's solution for volume preloading in spinal anaesthesia for elective caesarean section. Br J Anaesth. 1999; 83(3): 475-477, indexed in Pubmed: 10655924.

7. Riley ET. Editorial I: Spinal anaesthesia for Caesarean delivery: keep the pressure up and don't spare the vasoconstrictors. Br J Anaesth. 2004; 92(4):459-461, doi: 10.1093/bja/aeh084, indexed in Pubmed: 15013956.

8. Somboonviboon W, Kyokong O, Charuluxananan S, et al. Incidence and risk factors of hypotension and bradycardia after spinal anesthesia for cesarean section. J Med Assoc Thai. 2008; 91(2): 181-187, indexed in Pubmed: 18389982.

9. Lee A, Ngan KeeWD, Gin T. Prophylactic ephedrine prevents hypotension during spinal anesthesia for Cesarean delivery but does not improve neonatal outcome: a quantitative systematic review. Can J Anaesth. 2002; 49(6): 588-599, indexed in Pubmed: 12067872.

10. Nivatpumin $\mathrm{P}$, Thamvittayakul V. Ephedrine versus ondansetron in the prevention of hypotension during cesarean delivery: a randomized, double-blind, placebo-controlled trial. Int J Obstet Anesth. 2016; 27: 25-31, doi: 10.1016/j.ijoa.2016.02.003, indexed in Pubmed: 27020487.

11. Gan TJ. Selective serotonin 5-HT3 receptor antagonists for postoperative nausea and vomiting: are they all the same? CNS Drugs. 2005; 19(3): 225-238, indexed in Pubmed: 15740177.
12. Song JW, Park EY, Lee JG, et al. The effect of combining dexamethasone with ondansetron for nausea and vomiting associated with fentanyl-based intravenous patient-controlled analgesia. Anaesthesia. 2011; 66(4): 263-267, doi: 10.1111/j.1365-2044.2011.06648.x, indexed in Pubmed: 21401538.

13. Owczuk R, Wenski W, Polak-Krzeminska A, et al. Ondansetron given intravenously attenuates arterial blood pressure drop due to spinal anesthesia: a double-blind, placebo-controlled study. Reg Anesth Pain Med. 2008; 33(4): 332-339, doi: 10.1016/j.rapm.2008.01.010, indexed in Pubmed: 18675744.

14. SahooT, SenDasgupta C, Goswami A, et al. Reduction in spinal-induced hypotension with ondansetron in parturients undergoing caesarean section: a double-blind randomised, placebo-controlled study. Int J Obstet Anesth. 2012; 21(1): 24-28, doi: 10.1016/j.ijoa.2011.08.002, indexed in Pubmed: 22100822.

15. Ortiz-Gómez JR, Palacio-Abizanda FJ, Morillas-Ramirez F, et al. The effect of intravenous ondansetron on maternal haemodynamics during elective caesarean delivery under spinal anaesthesia: a double-blind, randomised, placebo-controlled trial. Int J Obstet Anesth. 2014; 23(2): 138-143, doi: 10.1016/j.ijoa.2014.01.005, indexed in Pubmed: 24631057.

16. Klöhr S, Roth R, Hofmann T, et al. Definitions of hypotension after spinal anaesthesia for caesarean section: literature search and application to parturients. Acta Anaesthesiol Scand. 2010; 54(8): 909-921, doi: 10.1111/j.1399-6576.2010.02239.x, indexed in Pubmed: 20455872. 